\title{
L-DOPA Treatment Selectively Restores Spine Density in Dopamine Receptor D2-Expressing Projection Neurons in Dyskinetic Mice
}

\author{
Luz M. Suárez, Oscar Solís, Jose M. Caramés, Irene R. Taravini, Jose M. Solís, \\ Mario G. Murer, and Rosario Moratalla
}

Background: L-3,4-dihydroxyphenylalanine (L-DOPA)-induced dyskinesia is an incapacitating complication of L-DOPA therapy that affects most patients with Parkinson's disease. Previous work indicating that molecular sensitization to dopamine receptor $\mathrm{D}_{1}$ (D1R) stimulation is involved in dyskinesias prompted us to perform electrophysiological recordings of striatal projection "medium spiny neurons" (MSN). Moreover, because enhanced D1R signaling in drug abuse induces changes in spine density in striatum, we investigated whether the dyskinesia is related to morphological changes in MSNs.

\begin{abstract}
Methods: Wild-type and bacterial artificial chromosome transgenic mice (D1R-tomato and D2R-green fluorescent protein) mice were lesioned with 6-hydroxydopamine and subsequently treated with L-DOPA to induce dyskinesia. Functional, molecular, and structural changes were assessed in corticostriatal slices. Individual MSNs injected with Lucifer-Yellow were detected by immunohistochemistry for three-dimensional reconstructions with Neurolucida software. Intracellular current-clamp recordings with high-resistance micropipettes were used to characterize electrophysiological parameters.
\end{abstract}

Results: Both D1R-MSNs and D2R-MSNs showed diminished spine density in totally denervated striatal regions in parkinsonian mice. Chronic L-DOPA treatment, which induced dyskinesia and aberrant FosB expression, restored spine density in D2R-MSNs but not in D1RMSNs. In basal conditions, MSNs are more excitable in parkinsonian than in sham mice, and excitability decreases toward normal values after L-DOPA treatment. Despite this normalization of basal excitability, in dyskinetic mice, the selective D1R agonist SKF38393 increased the number of evoked action potentials in MSNs, compared with sham animals.

Conclusions: Chronic L-DOPA induces abnormal spine re-growth exclusively in D2R-MSNs and robust supersensitization to D1Ractivated excitability in denervated striatal MSNs. These changes might constitute the anatomical and electrophysiological substrates of dyskinesia.

Key Words: Behavioral sensitization, dyskinesia, L-DOPA, medium spiny neuron, Parkinson's disease, striatum, three-dimensional neuronal reconstruction

A $\mathrm{n}$ almost complete loss of dopaminergic fibers in the motor region of the striatum results in the profound akinesia that characterizes advanced Parkinson's disease (PD) (1). At this stage most patients need chronic L-3,4-dihydroxyphenylalanine (L-DOPA) therapy, and many will develop L-DOPA-induced dyskinesia (2). Knowledge gained in recent years about the molecular mechanisms underlying dyskinesias has not yet resulted in improved therapies.

This might be due in part to the occurrence of structural changes in the striatal microcircuit. Postmortem studies have shown decreased total length of medium spiny neuron (MSN)

From the Instituto Cajal (LMS, OS, JMC, RM), Consejo Superior de Investigaciones Científicas, CSIC; CIBERNED (LMS, OS, JMC, RM), Instituto de Salud Carlos III; Hospital Universitario Ramón y Cajal (JMS), IRYCIS, Madrid Spain; Instituto de Investigaciones Farmacológicas (IRT), Consejo Nacional de Investigaciones Científicas y Técnicas; and the Departamento de Fisiología y Biofísica (MGM), Facultad de Medicina, Universidad de Buenos Aires, Buenos Aires, Argentina.

Address correspondence to Rosario Moratalla, Ph.D., Consejo Superior de Investigaciones Científicas, CSIC, Functional and System Neurobiology, Cajal Institute (CSIC), Avenida Doctor Arce 37, Madrid 28002, Spain; E-mail: moratalla@cajal.csic.es.

Received Dec 3, 2012; revised May 6, 2013; accepted May 8, 2013. dendrites in patients with advanced PD treated with L-DOPA (3). Subsequent studies revealed a decrease in spine density in MSNs of L-DOPA-treated patients $(4,5)$. In parallel, Ingham et al. $(6,7)$ showed a reduction of spine density in MSNs in rats with unilateral nigrostriatal lesion, a finding confirmed in additional animal models of PD (8-10). Although pruning of dendritic spines in striatal neurons at late stages of PD and in animal models of PD has been repeatedly reported, it is not clear whether it is modified by L-DOPA therapy.

Importantly, sensitization of dopamine receptor $D_{1}$ (D1R) signaling cascade in MSNs is causally related to the dyskinesias (11-17). A very similar D1R sensitization occurs in drug abuse $(18,19)$, but enhanced D1R signaling in addiction induces an increase in spine density in nucleus accumbens MSNs (20-25). Thus, D1R sensitization might induce similar structural changes in dyskinesias and drug abuse. Here we ask whether the dyskinesias are related to changes in the dendritic arbor of striatal MSNs. Moreover, because molecular sensitization to D1R stimulation is associated with an enhanced metabolic response of striatum to D1 agonists (15), we tested the hypothesis that striatal MSNs are more excitable in dyskinetic mice. We used a mouse model of parkinsonism induced by unilateral injection of 6-hydroxydopamine (6-OHDA) in the adult striatum $(16,26)$. The restricted pattern of nigrostriatal degeneration affecting the motor district of the striatum in this animal model allowed us to correlate morphological and functional changes in MSN to the degree of striatal denervation and to test whether the dyskinesias are associated with any additional alteration of MSN dendrites. 


\section{Methods and Materials}

This study was carried out in 3-4-month-old male C57BL6 wild-type (WT) and bacterial artificial chromosome (BAC)-transgenic mice (D1R-tomato or D2R-enhanced green fluorescent protein [eGFP]). Animals were housed and maintained following the guidelines from European Union Council Directive (86/609/ European Economic Community). Mice received an intrastriatal 6-OHDA (Sigma-Aldrich, Madrid, Spain) injection (parkinsonian group) or vehicle (sham group), as described previously (26). The mice recovered for 2-3 weeks and then began saline or L-DOPA treatment for 15 days (dyskinetic group). The treatment consisted of a daily intraperitoneal injection of $10 \mathrm{mg} / \mathrm{kg}$ benserazide hydrochloride (Sigma-Aldrich) followed 20 min later by an intraperitoneal injection of $25 \mathrm{mg} / \mathrm{kg}$ of L-DOPA (Sigma-Aldrich) or two saline injections 20 min apart.

\section{Behavior}

Dyskinesias were studied in WT, D1R-tomato, and D2R-eGFP mice three times/week, $30 \mathrm{~min}$ after treatment, as described previously (26). We measured orofacial and limb dyskinesias as well as axial dystonia individually with a 0-4 score scale for each animal. After the last L-DOPA injection, total axial, limb, and orofacial dyskinesia were measured every $20 \mathrm{~min}$ over a period of $180 \mathrm{~min}$ to see the dyskinetic profile over time.

\section{Immunohistochemistry}

Anesthetized animals were transcardially perfused with 4\% paraformaldehyde ( $\mathrm{pH}$ 7.4) 1 hour after the last L-DOPA injection. Brains were postfixed for 24 hours, and coronal sections were obtained on a vibratome (Leica, Madrid, Spain). The cutting sequence was 200-, 30-, 30-, and 30- $\mu$ m-thick sections throughout the entire striatum. The thicker sections were used for Lucifer-Yellow injections, whereas the 30- $\mu \mathrm{m}$ sections were used for tyrosine hydroxylase $(\mathrm{TH})$ and FosB immunostainings. Immunostaining was performed in free-floating sections with standard avidin-biotin protocols (27) with the following rabbit antisera: TH (1:1000; Chemicon, Temecula, California); FosB (1:7,500; Santa Cruz Biotechnology, Santa Cruz, California); and Lucifer-Yellow (1:100,000) (28).

\section{Morphology}

We used 200- $\mu \mathrm{m}$ sections from D1R-tomato and D2R-eGFP mice for morphological neuron reconstruction. The D1R- and D2R-positive MSNs from BAC-transgenic mice were visualized with the Cherry (for D1R-positive) or GFP (for D2R-positive neurons) fluorescence filters. To visualize D1R- or D2R-negative MSNs, striatal slices were labeled with 4',6-diamidino-2-phenylindole (Sigma-Aldrich). The MSNs were injected individually with Lucifer-Yellow (8\% in .05\% Tris-buffer, pH 7.4; Sigma-Aldrich) by passing a hyperpolarizing current (10-20 nA). Then, sections were processed for immunocytochemistry with the anti-Lucifer-Yellow antibody (see preceding text). Neurolucida (MicroBrightField, Williston, Vermont) was used to trace dendritic arbors of MSNs three-dimensionally and to mark spines. Only neurons that were completely filled were included for analysis. Filled neurons located near the lesion needle track were discarded. Quantifications were done by a researcher blind to the experimental conditions.

\section{Electrophysiology}

The WT mice (3-4-month-old) were decapitated, and their brains were removed and dropped into ice-cold Krebs-Ringerbicarbonate solution containing (in $\mathrm{mmol} / \mathrm{L}$ ): 119 sodium chloride,
26.2 sodium bicarbonate, 2.5 potassium chloride, 1 potassium dihydrogenorthophosphate, 1.3 magnesium sulphate, 2.5 calcium chloride, and 11 glucose, gassed with $95 \%$ oxygen and $5 \%$ carbon dioxide. Transverse corticostriatal slices $(400-\mu \mathrm{m}$-thick) were cut and stored for $>1$ hour at room temperature. Recordings were performed in a submersion-type chamber continuously perfused (1.8-2 $\mathrm{ml} / \mathrm{min})$ with standard Krebs-Ringer-bicarbonate solution at $31-32^{\circ} \mathrm{C}$. Stock solutions of picrotoxin $(5 \mathrm{mmol} / \mathrm{L}$; SigmaAldrich), SKF38393 hydrochloride (15 mmol/L; Sigma-Aldrich), and SCH23390 hydrochloride $(1 \mathrm{mmol} / \mathrm{L}$; Tocris, London, United Kingdom) were diluted to their final concentrations in the perfusion solution immediately before use. Intracellular recordings of dorsal striatal neurons were obtained with borosilicate glass micropipettes (1.5 mm outer diameter) pulled on a Flaming/ Brown puller (P-87; Sutter Instrument, Novato, California) and filled with $2 \mathrm{~mol} / \mathrm{L}$ potassium chloride (50-80 M $\Omega$ ), which were connected to an Axoclamp-2B amplifier (Axon Instruments, Foster City, California) used in bridge mode. The MSNs were identified by firing patterns (29). Input resistance (Rin) was calculated from the voltage defection produced by hyperpolarizing current pulses (.1-.2 nA) of 100-msec duration. Action potentials were elicited by 200-msec-long rectangular .3-.8-nA depolarizing pulses.

\section{Statistical Analysis}

Data were expressed as mean \pm SEM unless stated otherwise. Statistical differences (Systat-Software, San Jose, California; IBM SPSS Statistics version 20, Madrid, Spain) were assessed by oneor two-way analysis of variance followed by Bonferroni $t$ test; a value of $p<.05$ was considered statistically significant. Comparisons between cumulative frequency distribution were done with the Friedman test.

\section{Results}

\section{Induction of Dyskinesias in 6-OHDA-Lesioned Mice}

To quantify L-DOPA-induced dyskinesias in parkinsonian WT, D1R-tomato, or D2R-eGFP mice, we scored orofacial, limb, and locomotive dyskinesia $30 \mathrm{~min}$ after L-DOPA or saline injection as previously described $(14,16,26)$. After L-DOPA, parkinsonian BACtransgenic mice developed marked dyskinetic movements affecting the contralateral forelimb and orofacial structures, together with trunk dystonia, similar to those observed in WT mice (Figure 1A). These symptoms were not observed in the saline group. In all three genotypes, dyskinesias were maximal 30-60 min after L-DOPA, as observed in the time response curve performed on Day 14, and gradually declined to baseline levels over $180 \mathrm{~min}$ (Figure 1B), consistent with previous results $(16,26,30)$.

Previous studies have shown that dyskinesias in parkinsonian mice are related to increased phosphorylation of extracellular signal-regulated kinase- $1 / 2$ and augmented expression of $\Delta$ Fos $B$ and prodynorphin in the striatum [(26,31) reviewed in (19)]. We now show that, as shown previously in WT $(16,26)$, in the BACtransgenic mice, FosB induction only takes place in severely denervated striatal areas where the density of remaining dopaminergic fibers falls to $<10 \%$ of control levels (referred to here as the "totally denervated area"). Dyskinesias only appear when portions of the dorsolateral striatum are almost completely denervated, inducing substantial changes in FosB expression (Figure 1C) in all types of mice. There were no significant differences in $\mathrm{TH}$ or FosB expression between the different genotypes. 
A
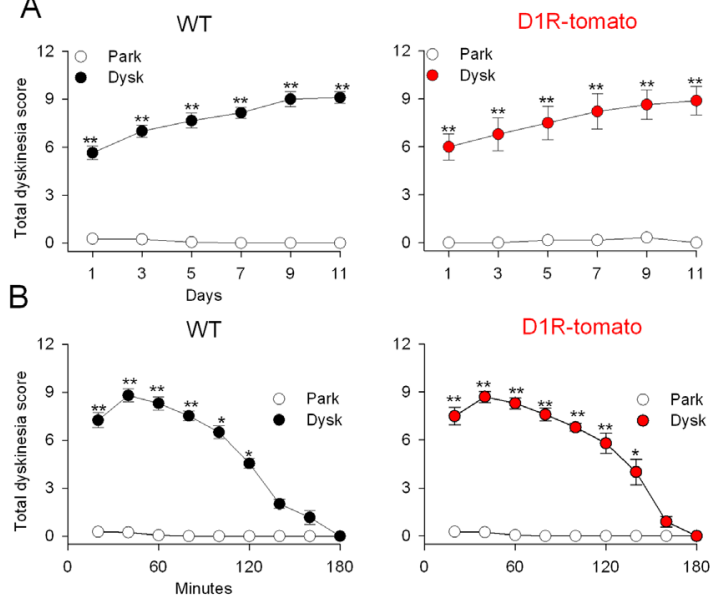
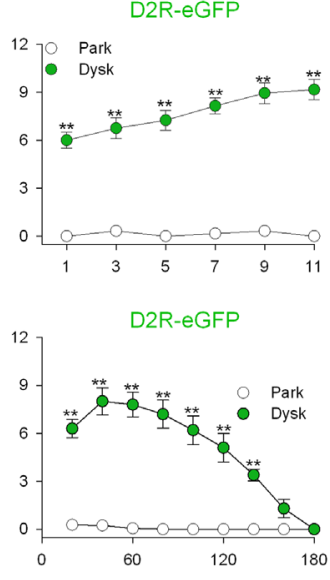

Figure 1. Dyskinesias and their molecular markers are similar in hemiparkinsonian wild-type (WT) mice and in dopamine receptor $D_{1}$ (D1R)-tomato and D2R-enhanced green fluorescent protein (eGFP) bacterial artificial chromosome transgenic mice. (A) Total dyskinesia (Dysk) score (axial dystonia plus limb and orolingual Dysk) in WT ( $n=$ $10)$, D1R-tomato $(n=8)$, and D2R-eGFP mice $(n=7)$. Measurements were taken $20 \mathrm{~min}$ after saline or L-DOPA treatment. (B) Duration of dyskinetic effect on Day 14. The total Dysk score was measured every $30 \mathrm{~min}$ for $180 \mathrm{~min}$. (C) Representative coronal striatal sections showing tyrosine hydroxylase (TH) (top) and FosB expression (bottom) from sham, parkinsonian, and dyskinetic WT, D1R-tomato, and D2R-eGFP mice. Note the correspondence between severe $\mathrm{TH}$ fiber depletion and expression of FosB $\left({ }^{*} p<\right.$ $.005 ;{ }^{* *} p<.001$ vs. saline, two-way analysis of variance). Park, parkinsonian mice.

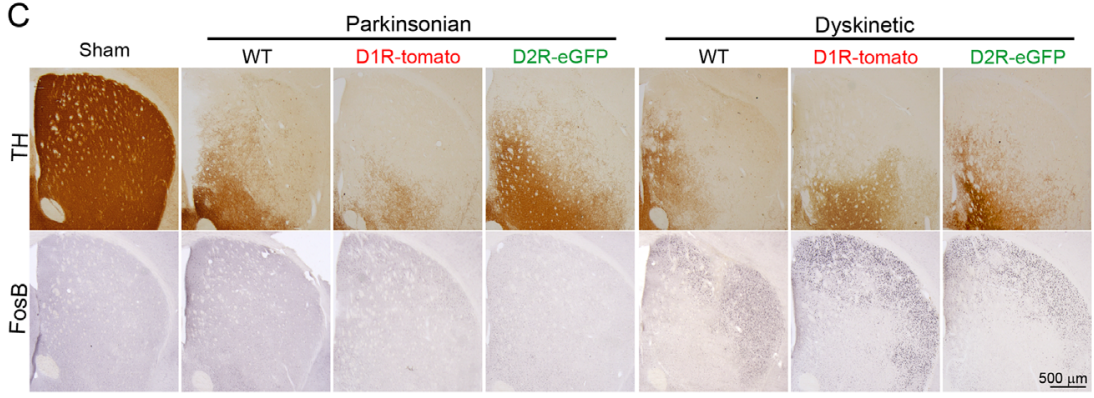

\section{Dopaminergic Denervation Does Not Alter MSN Dendritic} Arborization

In fixed striatal slices MSNs from WT, D1R-tomato, or D2R-eGFP mice were injected with Lucifer-Yellow through a microelectrode (Figure 2A-G). In D1R-tomato mice, we reconstructed D1Rpositive (red fluorescence) and D1R-negative (no fluorescence)
MSNs. Similar reconstructions were done of D2R-positive (greenfluorescence) and D2R-negative (no fluorescence) MSNs in D2ReGFP mice to test for possible compensatory mechanisms related to construction of BAC-transgenic mice.

To determine the effects of 6-OHDA lesion on the dendritic tree, MSNs were fully reconstructed from two areas: one with partial
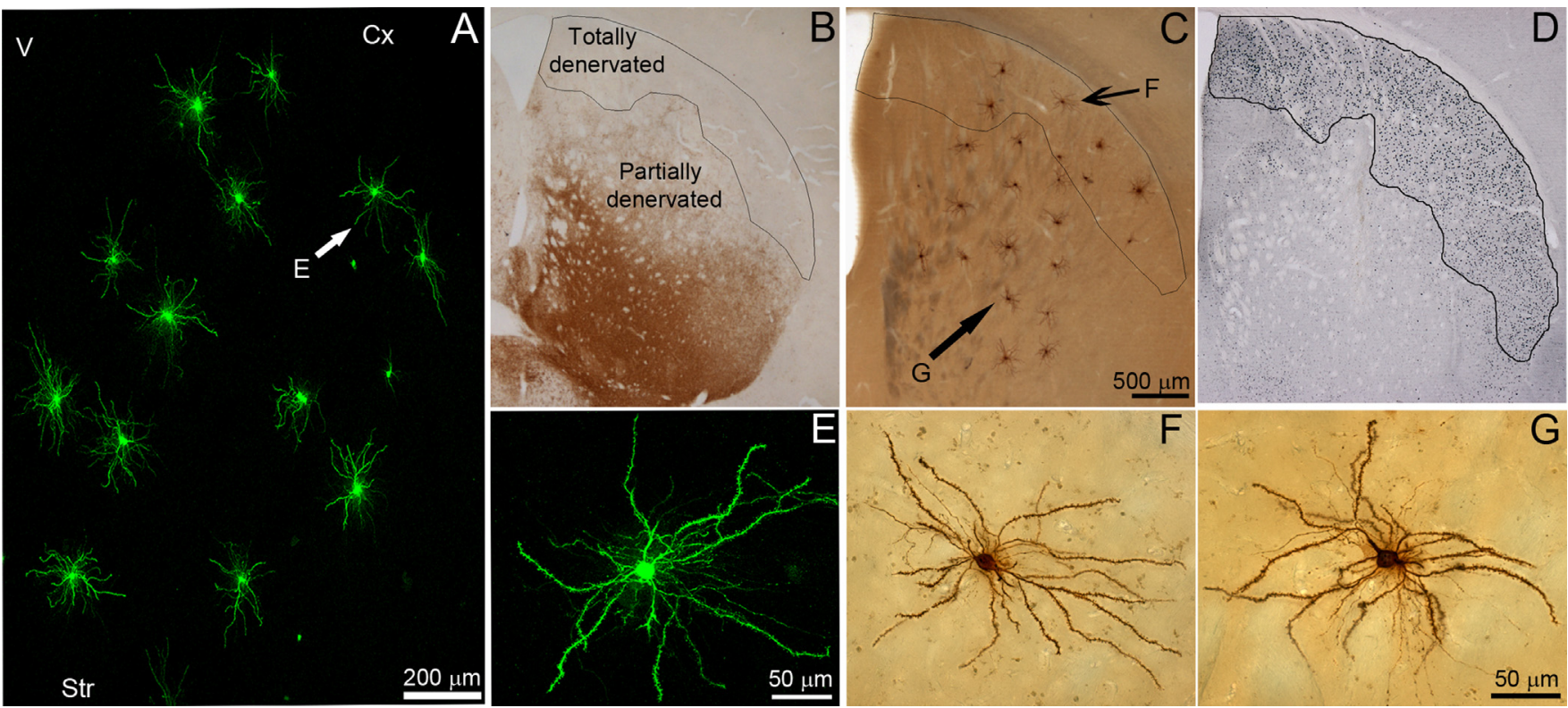

Figure 2. Complete morphological reconstruction of striatal medium spiny neurons (MSNs). (A) Lucifer-Yellow (LY) labeled MSNs in a 200- $\mu$ m-width coronal section of the striatum under low magnification. (B-D) Serial striatal sections showing TH (B), LY (C), and FosB (D) immunostaining from a dyskinetic mouse. The black line shows the boundary of the totally denervated striatal area $(<10 \%$ residual TH fibers). (E-G) High magnification microphotographs showing LY-injected MSNs before (E) and after (F, G) 3,3'-diaminobenzidine immunostaining. The MSNs shown in $\mathbf{E}$ and $\mathbf{F}$ are from a totally denervated area, and the one shown in $\mathbf{G}$ corresponds to a partially denervated area. Cx, cortex; Str, striatum; V, ventricle; other abbreviations as in Figure 1. 
A
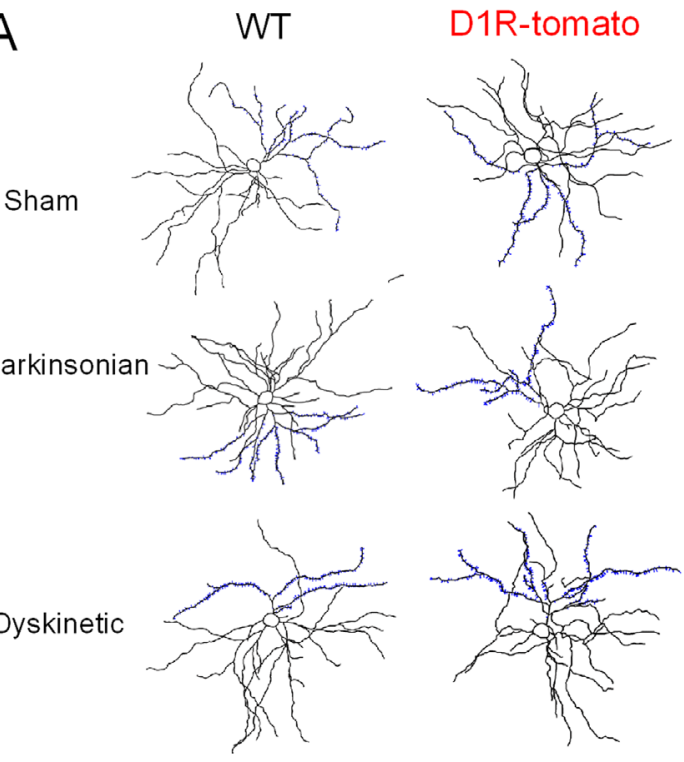

B

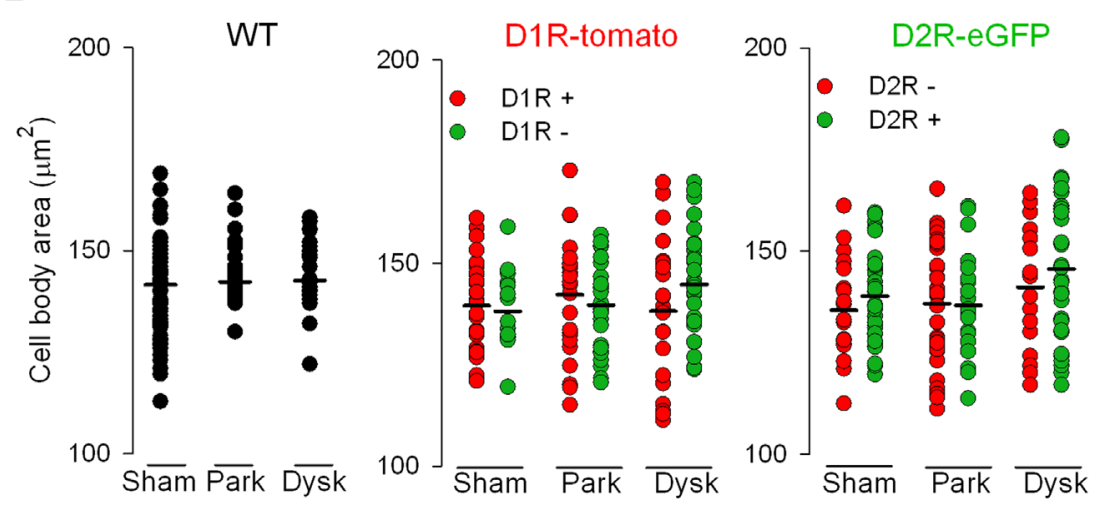

Figure 3. Cell body area of MSNs is not altered in parkinsonian or dyskinetic mice. (A) Drawings of representative MSNs in sham, parkinsonian, and in dyskinetic mice from WT, D1R-tomato, and D2R-eGFP mice. (B) Cell body area of MSNs from sham, parkinsonian, and dyskinetic WT, D1R-tomato, and D2R-eGFP mice. The WT mice group: $n=$ 35 from 7 sham; $n=45$ from 7 parkinsonian; and $n=57$ from 12 dyskinetic mice. The D1R-tomato mice group: D1Rpositive, fluorescence red, MSNs ( $n=28$ from 4 sham, $n=$ 27 from 5 parkinsonian, $n=22$ from 5 dyskinetic mice); and D1R-negative, no fluorescence, MSNs ( $n=16$ from 3 sham, $n=29$ from 5 parkinsonian, and $n=36$ from 6 dyskinetic mice). The D2R-eGFP mice group: D2R-negative, no fluorescence ( $n=20$ from 4 sham, $n=36$ from 6 parkinsonian, $n=20$ from 5 dyskinetic mice); and D2R-positive, green fluorescence MSNs ( $n=30$ from 6 sham, $n=27$ from 5 parkinsonian, and $n=35$ from 8 dyskinetic mice). Cell body area was similar in all experimental conditions. Lines represent the mean, and each circle represents a single neuron, in this and in the following figures. Abbreviations as in Figures 1 and 2. denervation; and a second with total denervation (defined by $\mathrm{TH}$ and FosB expression in adjacent sections) (Figure 2B-D). Figure 2F and $\mathrm{G}$ depicts representative MSNs from totally and partially denervated striatal areas, respectively. Full three-dimensional morphological reconstructions performed with NeuroLucida (MicroBrightField, Williston, Vermont) allowed us to assess the total length and degree of dendritic arborization of MSNs (Figure 3A). In WT mice there was no significant difference in MSN cell body area between parkinsonian (144 \pm 1.4$)$, dyskinetic (143 \pm .7$)$, and sham (142 \pm 1.4$)$ mice in totally (Figure $3 B$ ) or partially denervated striatal areas (Figure S1A in Supplement 1). Similarly, no changes were observed in identified MSN from D1R-tomato or from D2ReGFP mice, under these experimental conditions (Figure 3B).

The total length of dendrites was also unchanged in WT parkinsonian or dyskinetic mice (Figure 4A) and in identified MSN from D1R-tomato or D2R-eGFP mice, regardless of their localization in totally (Figure $4 \mathrm{~A}$ ) or partially denervated striatal areas (Figure S1B in Supplement 1). These results were further supported by Sholl analysis of the dendritic arbors. Parkinsonian and dyskinetic mice were not significantly different in total dendritic length (Figure 4B-E) or arborization (not shown) from sham mice. This was true in WT, D1R-tomato, and D2R-eGFP mice and was independent of MSN localization in totally or partially denervated areas (not shown). Thus, the data show that neither denervation nor chronic L-DOPA administration changed the total length or arborization of MSN in the mouse striatum.

\section{Spine Pruning Affects Both D1R- and D2R-MSNs in Highly Denervated Striatal Territories}

There is a debate about whether spine loss in the striatum preferentially affects the D2R-MSNs or equally affects D1R- and D2R-expressing MSNs (8-10). To answer this question, we assessed dendritic spines with two different BAC-transgenic mouse lines, D1R-tomato and D2R-GFP, in comparison with WT C57BL6 mice. We first assessed sham mice and observed that the number of dendritic spines in unidentified MSN from WT mice $(7.5 \pm .2)$ is similar to that in identified MSNs from D1R-tomato or D2R-eGFP mice (7.2 \pm .3 and $8.2 \pm .2$, respectively) (Figure 5B).

Striatal 6-OHDA lesion caused a significant decrease in spine density in totally denervated areas of WT mice (Figure 5B), as previously demonstrated (7). In D1R-tomato parkinsonian mice, spine density decreased equally in D1R-positive $(4.7 \pm .2)$ and -negative $(4.6 \pm .3)$ MSNs located within the totally denervated areas (Figure 5B). Similarly, dopaminergic denervation decreased spine density in both D2R-positive and -negative MSNs (Figure 5B). Cumulative frequencies of spine number of D1Rand D2R-positive MSNs indicate that 6-OHDA lesions reduce spine density similarly in both types of neurons (Figure 5C). A detailed study of spine density at increasing distances from the soma showed that the effect of total denervation was homogeneous along the dendritic arbor (Figures $6 \mathrm{~A}-\mathrm{C}$ ). Thus, total nigrostriatal denervation induces an almost 30\% decrease in the number of dendritic spines in both D1R- and D2R-MSNs (Figure 6B,C). This 

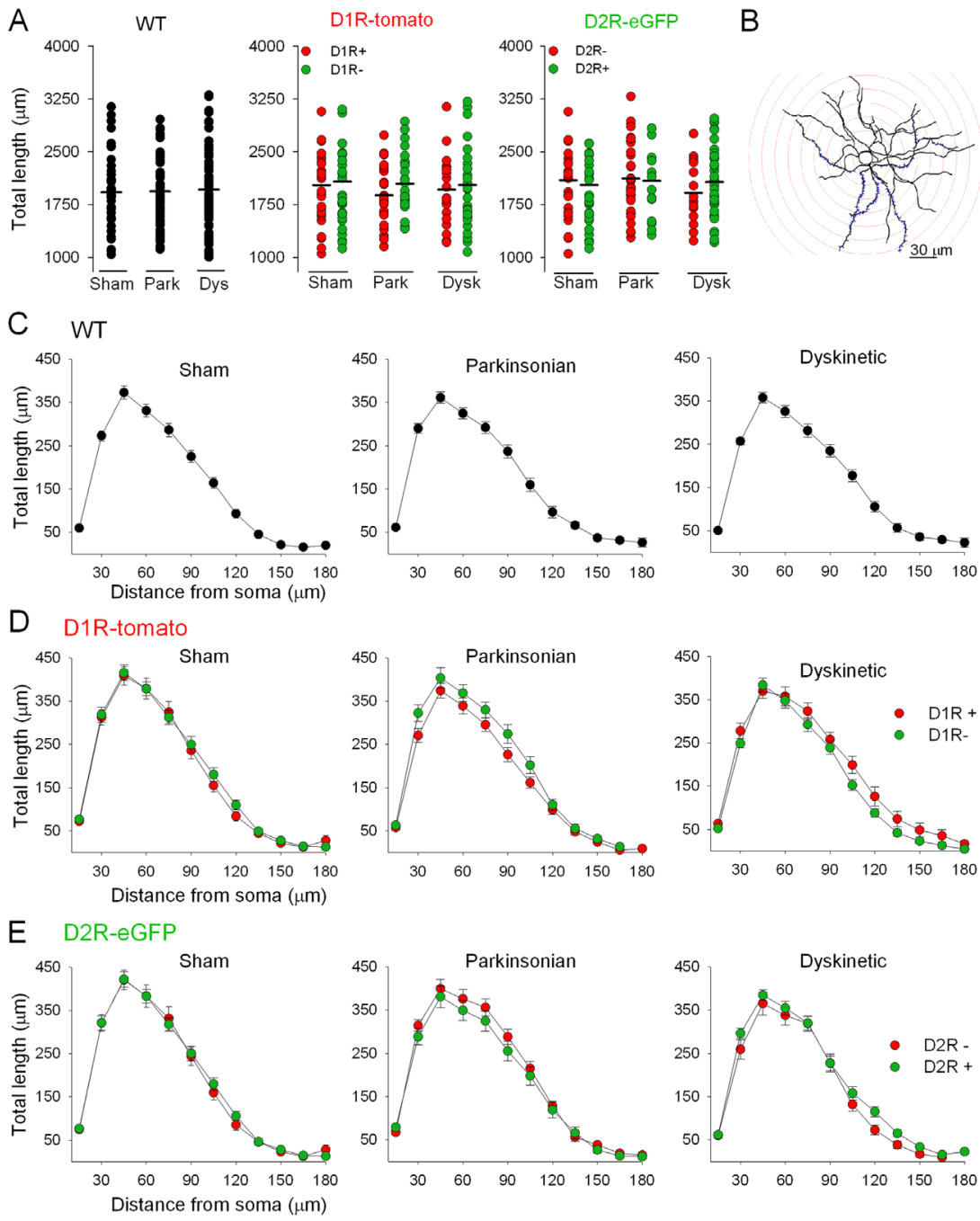

Figure 4. Total dendritic length of MSNs is not altered in parkinsonian or dyskinetic mice. (A) Total length of the dendritic arbor of MSNs located in totally denervated areas from WT, D1R-tomato, or D2R-eGFP mice in the different experimental conditions. (B) Concentric circles $(15 \mu \mathrm{m})$ centered in the cell body of a reconstructed MSN, illustrating the Sholl analysis of the dendritic arbor. (C-E) Total dendritic length as a function of distance from the soma in the different experimental groups: WT (C); D1Rtomato (D); or D2R-eGFP (E) mice. The $n$ is described in Figure 3. Abbreviations as in Figures 1 and 2. effect was dependent on the degree of denervation. In partially denervated striatal areas with a TH-loss $<90 \%$ there was no change in spine density in unidentified MSNs from parkinsonian WT mice or in identified neurons from parkinsonian D1R-tomato or D2R-eGFP mice (Figure 7).

\section{Chronic L-DOPA Selectivity Restores Spine Density in Denervated D2R-MSNs}

Studies in rodents treated with cocaine and psychostimulants show that repeated stimulation of dopamine receptors increases spine density in nucleus accumbens MSNs in correlation with behavioral sensitization (20-25). Because sensitization mechanisms underlie L-DOPA-induced dyskinesia, we checked whether similar changes in spine density occur in our mice. Chronic administration of L-DOPA at doses inducing dyskinesia significantly increased the number of spines on MSN from WT mice (Figures 5B and 6A), although spine density remained significantly lower than in sham animals.

To see whether this increase occurs in one or both types of MSN, similar experiments were carried out in BAC-transgenic mice. In dyskinetic D1R-tomato mice, L-DOPA treatment did not change the spine density of D1R-positive MSNs after denervation (4.4 \pm .3 compared with $4.7 \pm .2$, in dyskinetic and parkinsonian mice, respectively) (Figure 5B). By contrast, the number of spines in D1Rnegative MSNs significantly increases after L-DOPA treatment, from $4.6 \pm .3$ to $7.3 \pm .4(p<.005)$ (Figure 5B). Strikingly, after L-DOPA, spine density in the D1R-negative MSNs reaches normal density values observed in sham mice $(8.2 \pm .2)$. Our findings in D2R-eGFP mice confirmed these results (Figure $5 B$ ). As expected, spine density was similar in D2R-negative and D1R-positive MSN (4.4 \pm .3 and $4.4 \pm .3$, respectively), and the number of spines in D2R-positive and D1R-negative MSN was similar to sham control mice $(8.6 \pm .3$, $7.3 \pm .3$, and $8.0 \pm .3$, respectively). Cumulative frequencies of spine number of D1R- and D2R-positive MSNs indicate that L-DOPA increases spines in D2R-positive MSNs but not in D1R-positive MSNs of dyskinetic mice (Figure 5C). These results indicate that L-DOPA treatment induces reversal of denervation-induced spine pruning, selectively in D2R-containing MSNs.

Sholl analysis confirmed that spine density increases in D1Rnegative and D2R-positive MSNs from dyskinetic mice were homogeneous along the dendritic arbor $(45-165 \mu \mathrm{m})$ (Figure 6B,C). Chronic L-DOPA administration had no effect on the number of dendritic spines on MSNs in partially denervated striatal areas in any of the genotypes examined (Figure 7). Thus, unlike psychostimulants in intact brains, which increase MSN spine density above normal levels, L-DOPA increases spine 
A
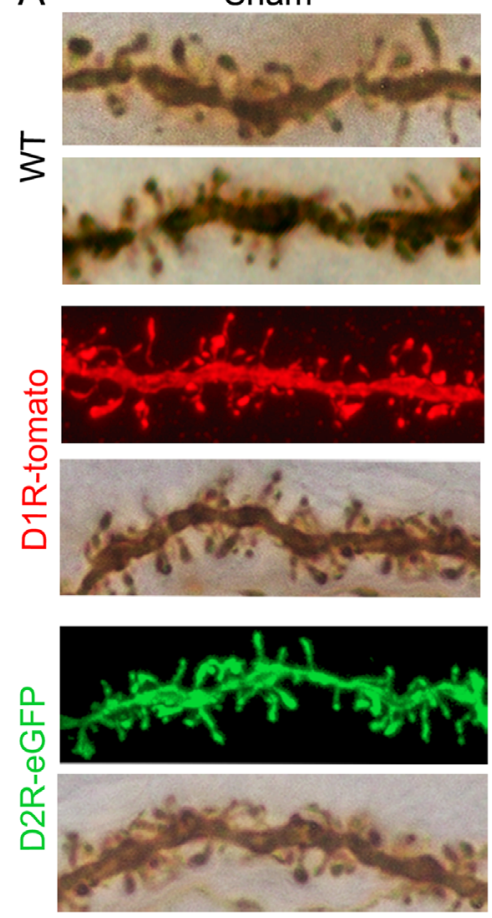

B

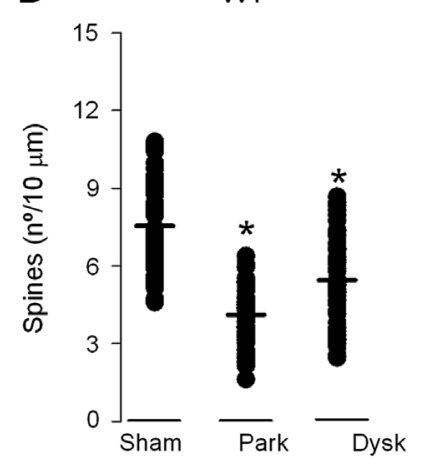

C

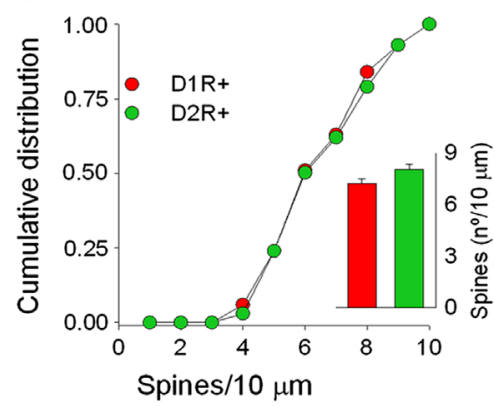

Parkinsonian
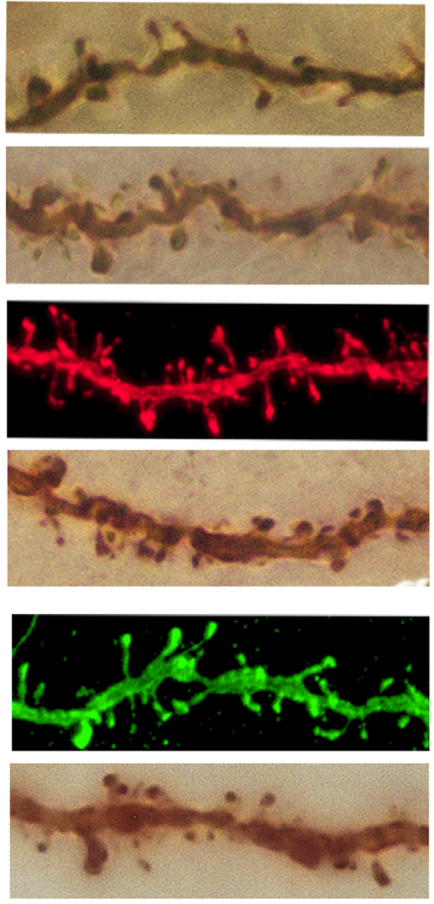

D1R-tomato

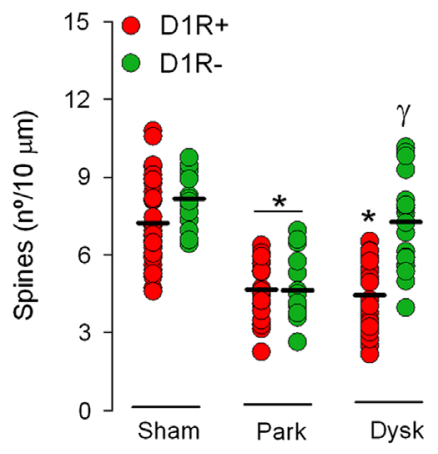

Parkinsonian

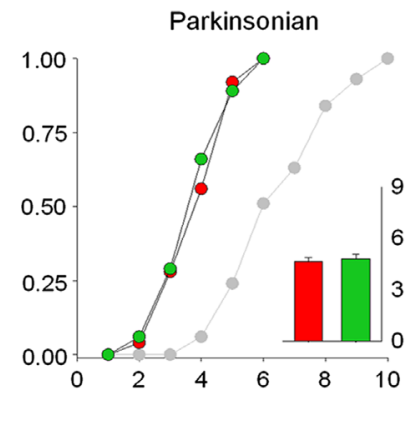

Dyskinetic
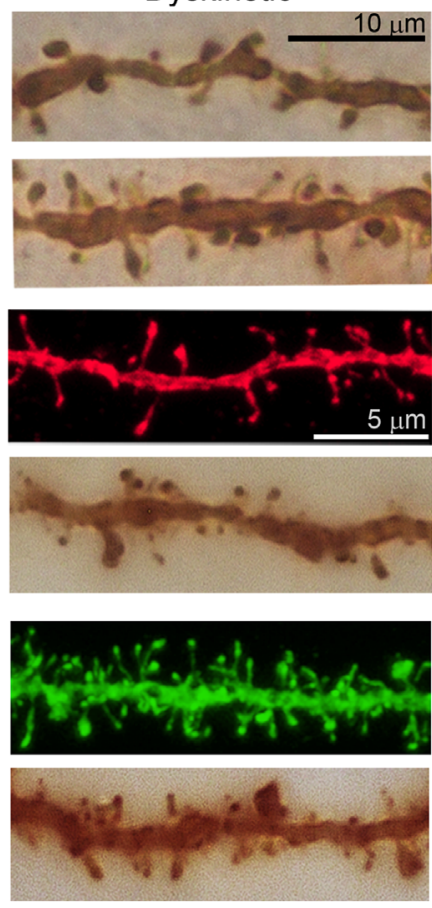

\section{D2R-eGFP}
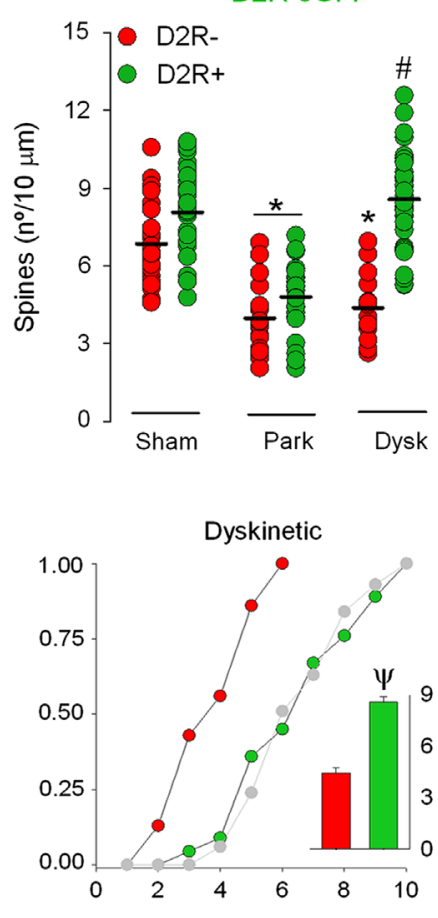

Figure 5. Chronic L-DOPA treatment selectively upregulates spine density in totally denervated D2R-MSNs. (A) Representative examples of confocal and optic microscopic images of MSN dendrites of WT (top), D1R-tomato (central), and D2R-eGFP (bottom) mice under different experimental conditions. The color of LY fluorescence was altered to show D1R-positive MSNs from D1R-tomato mice in red and D2R-positive MSNs from D2R-eGFP mice in green. (B) Average spine density along the MSN dendritic arbor (45-105 $\mu \mathrm{m}$ from soma) from WT, D1R-tomato, or D2R-eGFP mice in the different experimental conditions in totally denervated areas. Spine density of MSNs decreased in all parkinsonian groups. The L-DOPA treatment selectively restored spine number in D1R-negative and in D2R-positive MSNs from D1R-tomato and from D2R-eGFP dyskinetic mice, respectively. (C) Cumulative frequencies of spine density of D1R-positive and D2R-positive MSNs of sham-lesioned, parkinsonian, and dyskinetic mice. Gray traces in the graphic represent MSNs from sham mice to facilitate comparison between experimental groups. Inset bar graphs show the average \pm SEM of spine density to facilitate the comparison between the direct and indirect striatal pathway projection neurons (the $n$ is described in Figure $3 ;{ }^{*} p<.05$ vs. sham; $\gamma<.001$ vs. D1R-positive; ${ }^{*} p<.001$ vs. D2R-negative, two-way ANOVA; ${ }^{\Psi} p<.05$ Kruskal-Wallis test). Abbreviations as in Figures 1 and 2. 

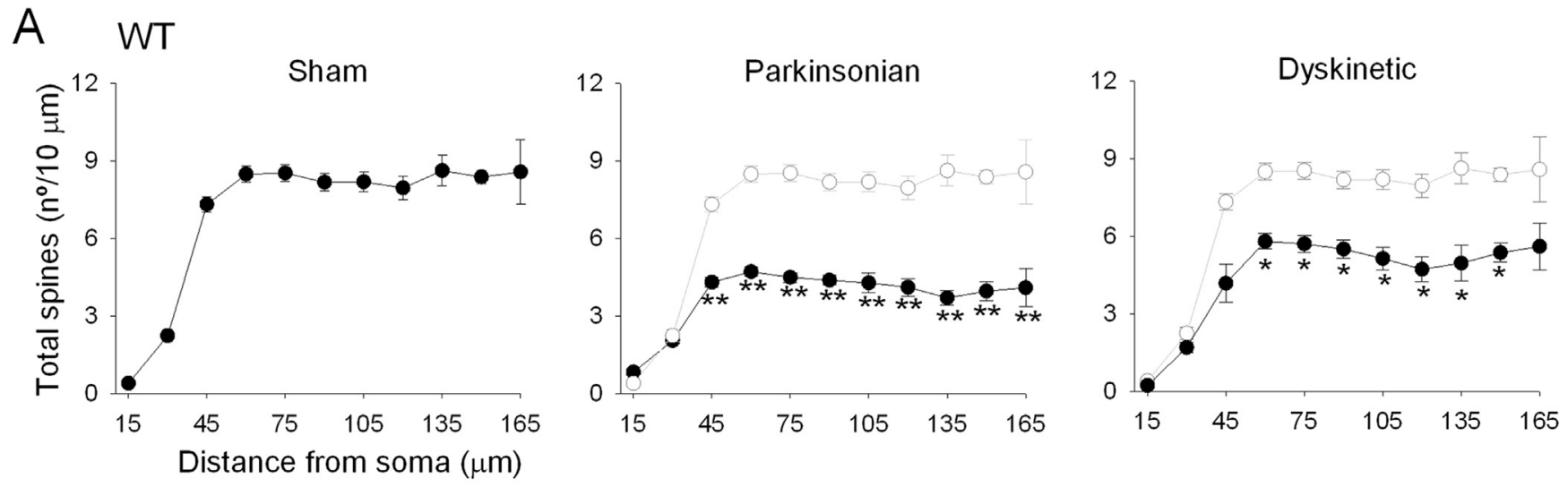

B D1R-tomato
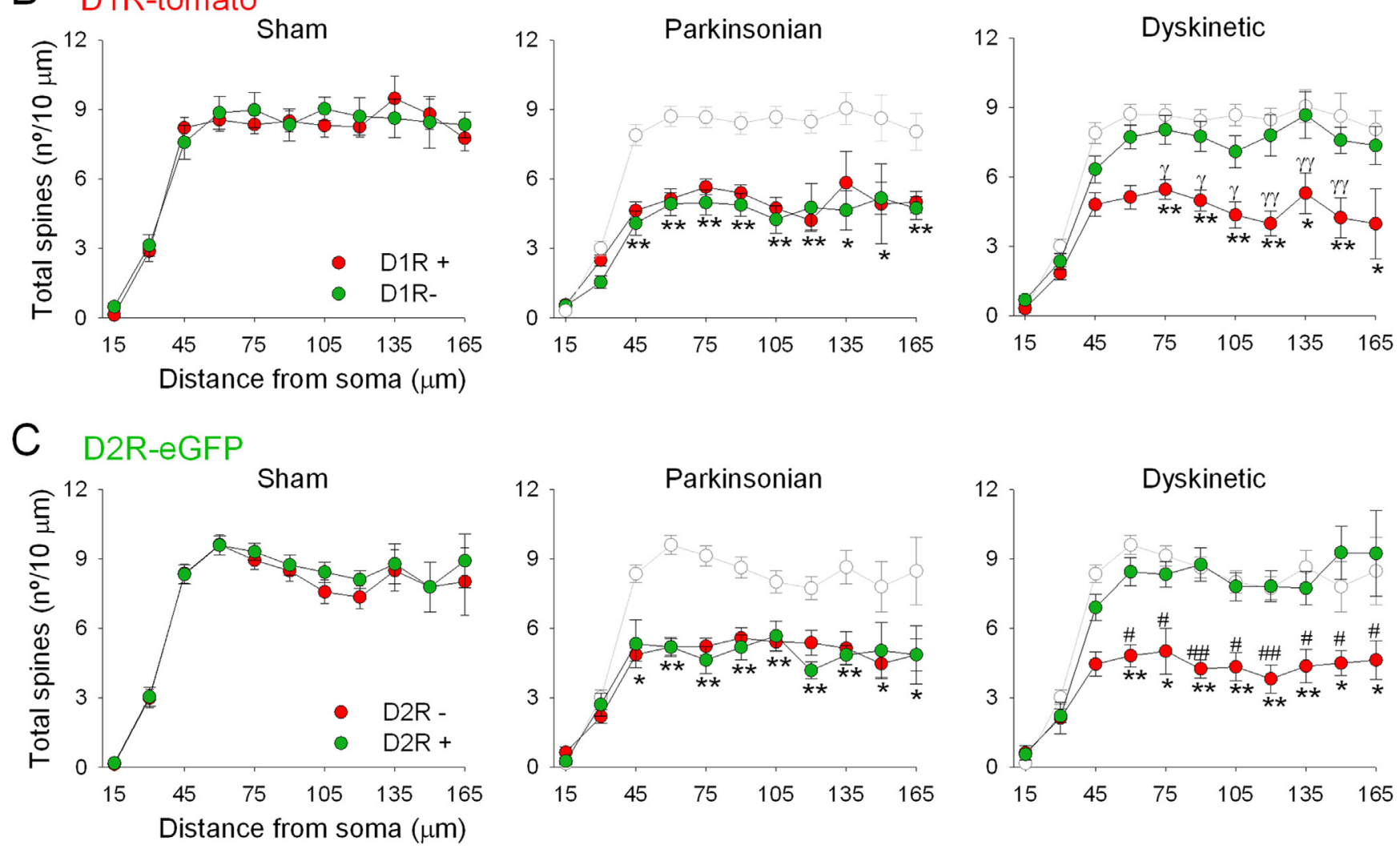

Figure 6. Chronic L-DOPA treatment restores spine density along the dendritic arbor of D2R-MSNs located in dopamine depleted areas. (A-C) Spine density as function of distance from the soma in WT (A), D1R-tomato (B), and D2R-eGFP (C) mice under the different experimental conditions. The 6-hydroxydopamine lesions (parkinsonian mice) decreased the spine density of MSNs along dendrites ( $>45 \mu \mathrm{m}$ from cell body in all three types of mice). The L-DOPA treatment (dyskinetic mice) selectively restored spine number in D1R-negative (B) and in D2R-positive (C) MSNs from D1R-tomato and D2ReGFP, respectively. Gray traces in the graphic represent MSNs from sham mice to facilitate comparison between experimental groups. The $n$ is described in Figure 3 ( $^{*} p<.05 ;{ }^{* *} p<.001$ vs. sham; ${ }^{\gamma} p<.05$, and ${ }^{\gamma \gamma} p<.001$ vs. D1R-negative MSNs; ${ }^{\sharp} p<.05$ and ${ }^{\#} p<.001$ vs. D2R-negative MSNs, two-way analysis of variance). Abbreviations as in Figures 1 and 2.

density selectively in D2R-MSNs located within regions where spines are lost after denervation, restoring it to normal levels.

\section{Enhanced Responsiveness to D1R Stimulation in Striatal Neurons Contributing to Dyskinesia}

Previous studies (32-34) have demonstrated changes in MSN excitability in dopamine denervated striatum. Moreover, current models propose that dyskinesia is related to hyperactivity of D1RMSNs $(14,16,26,30,35,36)$. We performed experiments to establish the functional consequence of dopamine depletion and L-DOPA treatment on intrinsic electrical properties of MSNs in corticostriatal slices from sham, parkinsonian, and dyskinetic mice. Many electrophysiological properties of MSNs in denervated striatal regions were not altered by nigrostriatal denervation or by L-DOPA treatment, including resting membrane potential, Rin, and action potential amplitude (32) (Table 1). With somatic current-clamp recordings, we characterized the pattern of action potentials evoked by depolarizing pulses applied through the recording pipette and found that MSNs were significantly more excitable in parkinsonian than sham mice. Chronic L-DOPA almost completely restored normal 

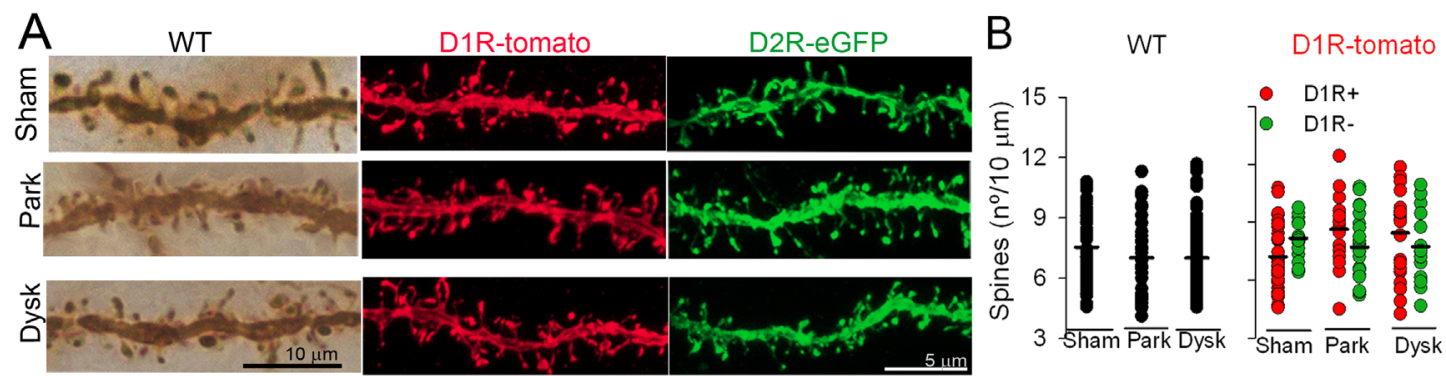

\section{D2R-eGFP}

C WT
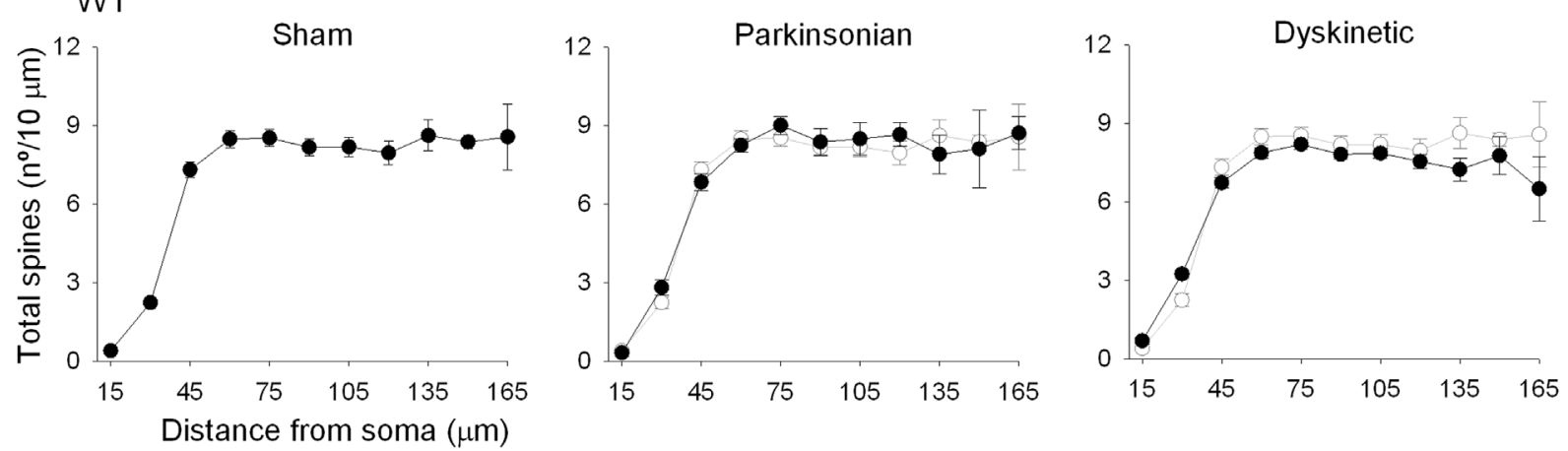

D D1R-tomato
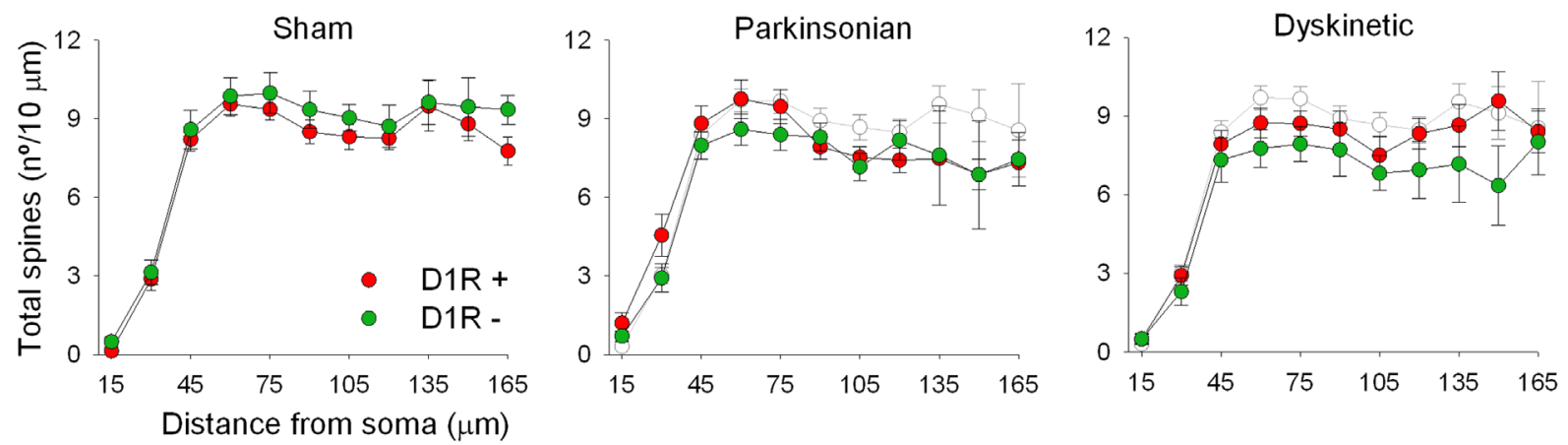

\section{E D2R-eGFP}
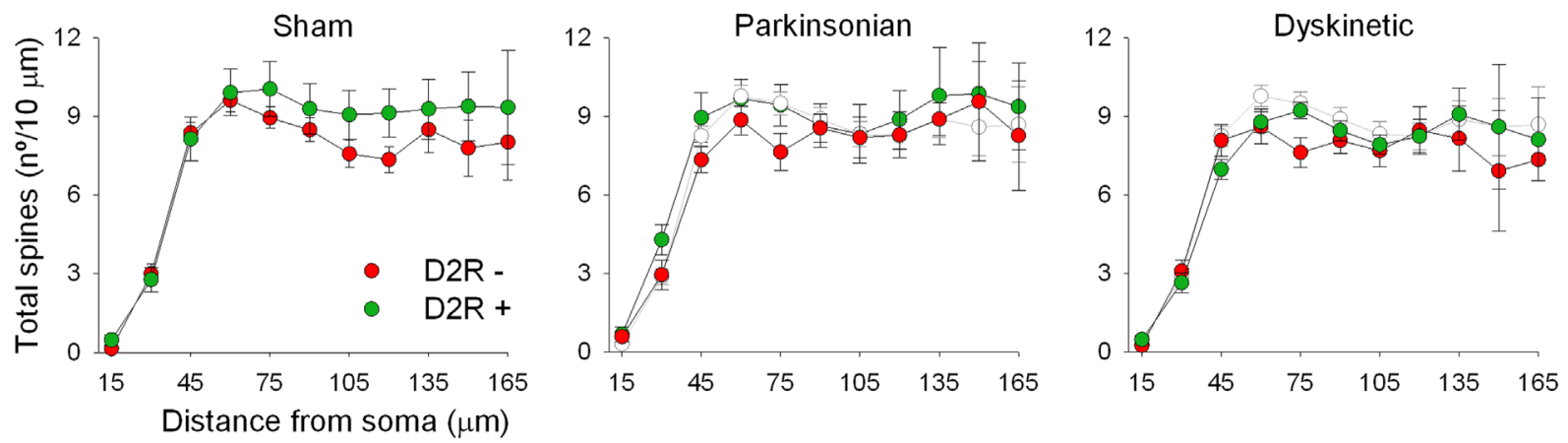

Figure 7. Partial dopaminergic denervation is sufficient to sustain normal spine density in MSNs. (A) Representative examples of confocal and optic microscopic images of dendritic spines of MSNs located in partially denervated areas from WT D1R-tomato, and D2R-eGFP mice under the different experimental conditions. The color of LY fluorescence was altered to show positive MSNs from D1R-tomato mice in red and from D2R-eGFP mice in green. (B) Average number of dendritic spines in MSNs (45-105 $\mu \mathrm{m}$ away from soma). (C-E) Spine Sholl analysis of MSN located in partially denervated areas of WT (C), D1R-tomato (D), and D2R-eGFP (E) mice. The WT group: $n=66$ from 7 sham; $n=38$ from 7 parkinsonian; and $n=62$ from 12 dyskinetic mice. The D1R-tomato group: D1R-positive, fluorescence red, MSNs ( $n=33$ from 4 sham, $n=17$ from 5 parkinsonian, $n=23$ from 5 dyskinetic mice); and D1Rnegative, no fluorescence, MSNs ( $n=17$ from 3 sham, $n=23$ from 5 parkinsonian, and $n=15$ from 6 dyskinetic mice). The D2R-eGFP group: D2Rnegative, no fluorescence ( $n=24$ from 4 sham, $n=17$ from 6 parkinsonian, $n=12$ from 5 dyskinetic mice); and D2R-positive, green fluorescence MSNs ( $n=30$ from 6 sham, $n=15$ from 5 parkinsonian, and $n=32$ from 8 dyskinetic mice). Abbreviations as in Figures 1 and 2. 
Table 1. Intrinsic Membrane Properties of MSNs

\begin{tabular}{|c|c|c|c|c|c|c|}
\hline & & \multirow[b]{2}{*}{$\mathrm{RMP}(\mathrm{mV})$} & \multirow[b]{2}{*}{$\operatorname{Rin}(m \Omega)$} & \multicolumn{3}{|c|}{ Action Potential } \\
\hline & & & & Amplitude (mV) & Duration (msec) & Firing Threshold $(\mathrm{mV})$ \\
\hline Sham & Saline & $-88.19 \pm .99$ & $45.63 \pm 1.44$ & $89.06 \pm 1.70$ & $.75 \pm .02$ & $48.98 \pm .74$ \\
\hline \multirow[t]{2}{*}{ Lesion } & Park & $-88.95 \pm 1.46$ & $47.94 \pm 2.58$ & $89.84 \pm 1.40$ & $.84 \pm .02^{a}$ & $52.55 \pm 1.29^{a}$ \\
\hline & Dysk & $-87.74 \pm 2.08$ & $46.52 \pm 2.46$ & $88.35 \pm 1.56$ & $.82 \pm .02$ & $52.32 \pm .84$ \\
\hline
\end{tabular}

Sham saline ( $n=19$ from 14 mice); L-DOPA ( $n=13$ from 9 mice); parkinsonian (Park) ( $n=14$ from 7 mice); dyskinetic (Dysk) ( $n=20$ from 9 mice). MSNs, medium spiny neurons; Rin, input resistance; RMP, resting membrane potential.

${ }^{a} p<.05$ parkinsonian vs. sham in saline treatment (one-way analysis of variance; Bonferroni post hoc).

excitability (Figure 8). Increased excitability in denervated animals coincided with a decrease in action potential threshold (Table 1).

The selective D1R agonist SKF38393 applied to the bath (3 or $10 \mu \mathrm{mol} / \mathrm{L}$ ) had no effect on depolarization-induced action potential firing in sham mice (Figure 9A,B) but increased evoked firing in parkinsonian mice. The effect was weak in vehicle-treated parkinsonian mice but was greatly enhanced in mice that had shown L-DOPA-induced dyskinesia ( $p=.02$ in parkinsonian mice) (Figure 9B). This increase was reversed by bath co-application of SKF38393 plus a selective D1R antagonist, SCH23390 (10 $\mu \mathrm{mol} / \mathrm{L})$ (Figure 9C). The D1R agonist-induced increase in firing rate was not associated with major changes in intrinsic properties of MSNs (Table 2). Thus nigrostriatal denervation enhances MSN excitability, whereas chronic L-DOPA enhances a positive modulatory effect of the D1R on excitability.

\section{Discussion}

Here we show that 6-OHDA lesions in the striatum reduce spine density in D1R-positive and D2R-positive MSN of D1R-tomato and D2R-eGFP BAC-transgenic mice. This reduction was similar to that observed in unidentified MSN in WT C57BL6 mice. We further show that these changes are restricted to totally denervated striatal areas. A major finding of the present study is that chronic L-DOPA, at doses inducing dyskinesia, reverses dendritic spine loss selectively in striatal MSNs expressing the D2R. These MSNs are part of the indirect, striatopallidal projection pathway. These results were obtained in D1R-negative MSN from D1R-tomato mice and in D2Rpositive MSN from D2R-eGFP mice. L-DOPA does not affect spine pruning in the D1R- MSNs, which form the direct striatonigral pathway. Moreover, MSNs showed an enhanced firing rate during current injection in parkinsonian animals. Although chronic L-DOPA reversed this hyperexcitability, it also enhanced a positive modulatory effect of the D1R on evoked firing. Thus, MSNs show more marked responses to injected current during D1R stimulation in dyskinetic than in parkinsonian mice.

We found that spine pruning only occurs in striatal regions with severe striatal denervation. Regions with more than $10 \%$ of dopaminergic fibers spared showed no sign of dendritic pathology. This is in general agreement with findings by Villalba et al. (10) in I-methyl-4-phenyl-l,2,3,6-tetrahydropyridine (MPTP)-lesioned monkeys, but Villalba et al. suggested a graded parallel pattern of dendritic pathology and dopaminergic fiber loss, whereas our results suggest a threshold of dopamine fiber depletion for dendritic pathology. However, because a graded pattern would be difficult to detect in the small mouse striatum, the possibility remains that, after a given threshold is surpassed, dendritic pathology is graded according to extent of dopamine fiber loss.
A
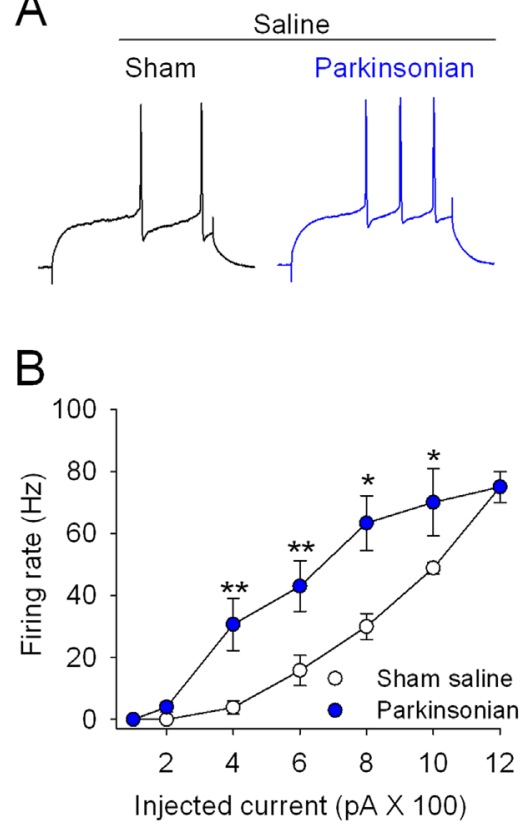

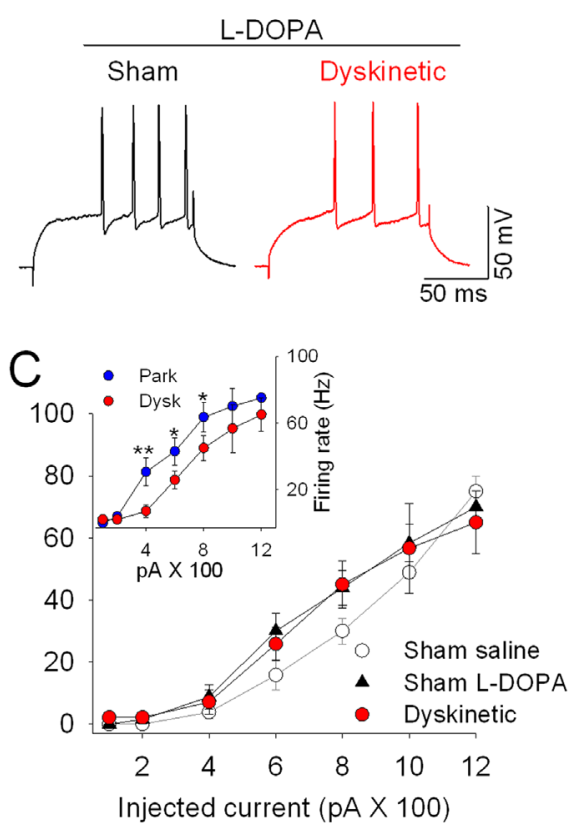

Figure 8. Enhanced excitability of MSNs in denervated striatum. (A) Representative recording of discharge evoked during current injection in MSNs of each experimental group. Note the enhanced response in parkinsonian compared with the sham saline condition. (B) Intensity response curves of saline-treated mice. (C) Intensity response curves of L-DOPA-treated mice. The sham saline curve is represented in $\mathbf{B}$ and $\mathbf{C}$ to facilitate visual comparisons. Inset graph shows the firing rate of MSNs from parkinsonian and dyskinetic mice to facilitate the comparison $\left({ }^{*} p<.01 ;{ }^{* *} p<.001\right.$ vs. sham, two-way repeated measures ANOVA). Of note, L-DOPA significantly reduced excitability in parkinsonian mice $(p<.01)$. Sham mice $(n=19$ neurons from 14 mice treated with saline; $n=13$ neurons from 9 mice treated with L-DOPA); parkinsonian mice ( $n=14$ neurons from 7 mice); and dyskinetic mice ( $n=20$ neurons from 9 mice). Abbreviations as in Figures 1 and 2. 
A

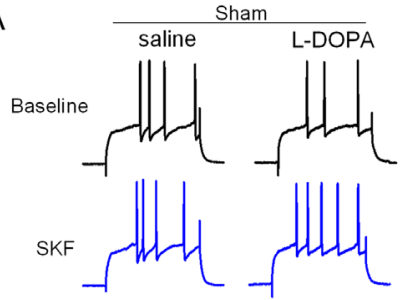

B
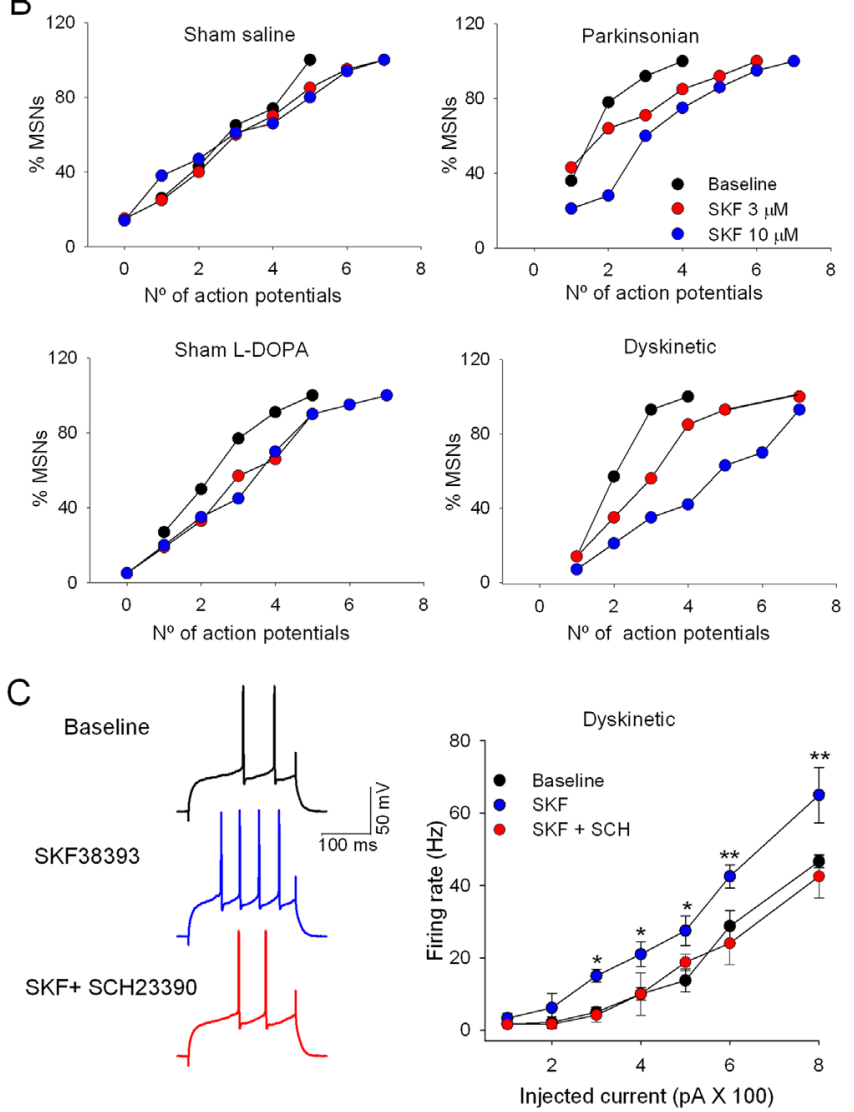

Figure 9. Enhanced responsiveness to D1 receptor stimulation in the denervated striatum. (A) Representative traces of MSNs in the different experimental groups, before (black) and during (blue) application of the selective D1 agonist SKF38393 to the bath $(10 \mu \mathrm{mol} / \mathrm{L})$. (B) Percentage of MSNs that fire action potential in response to SKF38393 (3 or $10 \mu \mathrm{mol} / \mathrm{L}$, as indicated) application in sham mice treated with saline $(n=19$ from 14 mice) or L-DOPA ( $n=13$ from 9 mice) and in parkinsonian ( $n=14$ from 7 mice) and dyskinetic mice ( $n=20$ from 9 mice). Significant effects were seen at SKF38393 $(10 \mu \mathrm{mol} / \mathrm{L})$ in dyskinetic mice $(p<.05$, Friedman test). (C) Representative traces (right) showing evoked action potentials (400 pA current pulse) of MSN from dyskinetic mice recorded under basal conditions, during bath application of SKF38393 (10 $\mu \mathrm{mol} / \mathrm{L})$ alone (blue) or with $\mathrm{SCH} 23390(10 \mu \mathrm{mol} / \mathrm{L}$; red). The firing rate as function of injected current (left) in MSNs from dyskinetic mice ( $n=6$ from 3 mice). The firing rate increases during bath application of $10 \mu \mathrm{mol} / \mathrm{L}$ SKF38393 (blue scatterplot) $\left({ }^{*} p<.05 ;{ }^{* *} p<.001\right.$ vs. baseline, two-way analysis of variance) and returns to basal values during the co-application with SCH23390 (red plot). Abbreviations as in Figures 1 and 2.

There is a debate about whether spine loss in the parkinsonian striatum preferentially affects the D2R-MSNs projecting to the globus pallidus (indirect pathway) or equally affects D1R-MSNs (direct pathway) and D2R-MSNs (8-10). Day et al. (8) reported that spine loss is limited to D2R-MSNs in mouse models of parkinsonism. Then, in MPTP-lesioned monkeys, Scholz et al. (9) confirmed spine depletion in D2R-MSN but showed an augmented spine density in D1R-MSNs. Finally, Villalba et al. (10) found a similar depletion of spines in D1R-positive neurons and putative D2Rexpressing neurons in MPTP-lesioned monkeys. Our results show that spine pruning affects both D1R- and D2R-MSNs in parkinsonian mice. Moreover, the spine decrease was found in two different BAC-transgenic animal lines: D1R-tomato and D2R-eGFP mice. We cannot explain the discrepancy between our results and those of Day et al., although different models of parkinsonism were used (reserpine vs. intrastriatal 6-OHDA injections) as well as different techniques (ex vivo vs. postmortem neuronal filling) and different-age mice (25-day vs. 3-4-month old).

One of the aims of the present study was to determine whether dendritic pathology is modified by L-DOPA treatment. This is important because the dendritic pathology observed in patients could be a consequence of the natural history of the disease, of treatment, or of an interaction between the two. Although the available human studies included control subjects without any known brain pathology, all PD patients in these studies received L-DOPA chronically $(4,5)$. Our results here demonstrate that dopamine denervation-induced spine pruning is reversed by L-DOPA treatment in D2R-MSNs but not in D1R-MSNs. It has been suggested that spine pruning after dopamine denervation is induced by an increase in glutamatergic transmission $(8,37,38)$. It is possible that L-DOPA restores striatal glutamatergic release to normal levels $(39,40)$, producing a recovery of spines in MSNs. The question then is: "Why does spine recovery occur selectively in D2R-MSNs?" Although morphological studies evidence a similar glutamatergic innervation to D1R- and to D2R-MSNs (41), electrophysiological studies (38) showed that D2R-MSNs have stronger cortical inputs and are more directly affected by cortical activity than D1R-MSNs. Although specific studies in dyskinetic animals are lacking, indirect evidence suggests that L-DOPA treatment would inhibit the response of D2R-MSNs to cortical input $(42,43)$. Thus, L-DOPA treatment could increase the number of spines in D2R-MSN in an attempt to overcome the inhibition. By contrast, L-DOPA-induced dyskinesia is associated with alterations in glutamate (AMPA and NMDA) and dopamine (D1) receptor interaction and trafficking within the postsynaptic membrane (44-46). Moreover, D1R stimulation during L-DOPA treatment could be expected to potentiate glutamate effects on D1R-MSNs $(43,47)$. Thus, it is possible that, although glutamate release returns to normal levels after L-DOPA, postsynaptic glutamatergic transmission remains altered in D1R-MSNs, blocking the recovery of spines because of the aforementioned abnormal dopamine-glutamate receptor interaction. These points are in line with the opposing role of dopamine receptors on glutamatergic transmission (D1R potentiate, whereas D2R inhibit glutamate-mediated currents) and might relate to changes to maintain, as far as possible, the cellular homeostasis.

Although spine re-growth in D2R-MSNs in dyskinetic mice might respond to the restoration of glutamate levels and D2Rmediated inhibition in the striatum, a remaining issue is whether these new spines form physiological synapses. We think this is unlikely, because spine re-growth is not accompanied by physiological dopaminergic re-innervation. If these new spines do form synapses, with which cell types do they synapse? One possibility is that they make contact with glutamatergic afferents (39), forming abnormal synapses in the absence of tonic dopamine modulation and setting the grounds for L-DOPA-induced dyskinesia.

Previous studies showed that MSN membrane excitability is enhanced in denervated striatum $(32,34)$. Here, we extend these results by showing that, in parkinsonian mice, the action potential 
Table 2. Intrinsic Membrane Properties of MSNs Measured After SKF38393

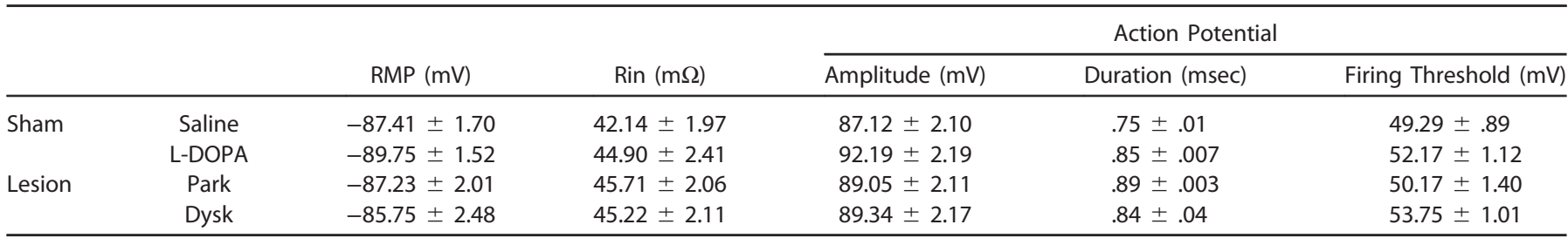

Intrinsic membrane properties of MSNs measured after SKF38393, $10 \mu \mathrm{mol} / \mathrm{L}$ bath application $(7 \mathrm{~min})$. Sham saline $(n=19$ from $14 \mathrm{mice}) ; \mathrm{L}-\mathrm{DOPA}(n=$ 13 from 9 mice); Park ( $n=14$ from 7 mice); Dysk $(n=20$ from 9 mice). Abbreviations as in Table 1.

threshold is decreased and the firing rate induced by current injection is increased. One candidate to mediate lesion-induced changes in excitability is A-type potassium current, which has well-known effects on action potential firing and whose inactivation is regulated by dopamine in MSNs (48). In fact, Azdad et al. (34) found that A-type potassium current inactivation is faster in parkinsonian than in control rats, resulting in an augmented excitability similar to what we found here in parkinsonian mice. It has been proposed that the high basal excitability of MSN in nontreated dopamine-depleted animals represents a homeostatic mechanism that maintains neuronal firing despite the loss of excitatory synapses (34). A remaining question is whether this hyperexcitability at single cell level is associated with anomalous neuronal synchronization and changes in network dynamic status after dopamine depletion (49).

L-DOPA treatment restores evoked firing in response to current injection to nearly normal levels, but our data also show that the L-DOPA-induced dyskinesia is accompanied by a marked sensitization, enhancing the effects of D1R stimulation in MSNs without changes in the firing threshold. Our results show a slight although not significant depolarization of MSNs in dyskinetic mice during SKF38393 bath application (Tables 1 and 2), which could explain the increase in D1R-mediated responses. Previous work has shown dual effects of D1R on MSN excitability through the modulation of sodium-, potassium-, and calcium-voltage-dependent currents, which are available at different membrane potentials observed in vivo $(50,51)$. Thus, D1R modulation of any of these currents might be altered in dyskinetic mice. Because no D1R enhancing effect on excitability is seen in slices from sham mice treated with L-DOPA (32,52), it must be considered as an abnormal response to nigrostriatal denervation, which is further enhanced in dyskinesias. This striatal hyperexcitability to D1R stimulation might mediate the widespread metabolic and electrophysiological changes observed in dyskinetic animals and patients (15,53-56). We speculate that, in dyskinetic mice, the firing response of MSNs to injected current during application of a D1R agonist reflects more closely what happens in patients taking L-DOPA than the baseline slice condition where dopamine is low in parkinsonian mice.

Overall, our findings reveal two new correlates of dyskinesia: L-DOPA restores spine density selectively in D2R-MSNs and induces an abnormal D1R-mediated enhancement of MSN firing responses to membrane depolarization. These changes might contribute to the postulated functional imbalance favoring the direct over the indirect pathway, which is predicted by basal ganglia models to underlie dyskinesia. New experiments are necessary to determine whether the new spines induced in D2R-MSNs by L-DOPA form functional synapses.

This work was supported by grants from the Spanish Ministries de Economía y Competitividad and Sanidad y Política Social, ISCIII: BFU2010-20664, PNSD, RedRTA (RD06/0001/1011), CIBERNED ref.
CB06/05/0055, and Comunidad de Madrid ref. S2011/BMD-2336 to RM; Spanish Ministries de Ciencia e Innovación (MICINN) PIU081067 to JMS Fondo Nacional para la Investigación Científica y Tecnológica, Argentina, PICT 2008-2205/PICT 2011-521, Consejo Nacional de Investigaciones Científicas y Tecnológicas, Argentina, PIP 2009-77, and Universidad de Buenos Aires, UBACYT M562, to MGM.

We would like to thank Ms. Emilia Rubio and Mr. Marco de Mesa for their excellent technical assistance and Dr. J DeFelipe for providing the Lucifer-Yellow antibody.

The authors report no biomedical financial interests or potential conflicts of interest.

Supplementary material cited in this article is available online at http://dx.doi.org/10.1016/j.biopsych.2013.05.006.

1. Kish SJ, Shannak K, Hornykiewicz O (1988): Uneven pattern of dopamine loss in the striatum of patients with idiopathic Parkinson's disease. Pathophysiologic and clinical implications. N Engl J Med 318: 876-880.

2. Nutt JG (2000): Response to L-dopa in PD: The long and the short of it. Neurology 54:1884-1885.

3. McNeill TH, Brown SA, Rafols JA, Shoulson I (1988): Atrophy of medium spiny I striatal dendrites in advanced Parkinson's disease. Brain Res 455:148-152.

4. Stephens B, Mueller AJ, Shering AF, Hood SH, Taggart P, Arbuthnott GW, et al. (2005): Evidence of a breakdown of corticostriatal connections in Parkinson's disease. Neurosci 132:741-754.

5. Zaja-Milatovic S, Milatovic D, Schantz AM, Zhang J, Montine KS, Samii A, et al. (2005): Dendritic degeneration in neostriatal medium spiny neurons in Parkinson disease. Neurology 64:545-547.

6. Ingham CA, Hood SH, Arbuthnott GW (1989): Spine density on neostriatal neurones changes with 6-hydroxydopamine lesions and with age. Brain Res 503:334-338.

7. Ingham CA, Hood SH, Taggart P, Arbuthnott GW (1998): Plasticity of synapses in the rat neostriatum after unilateral lesion of the nigrostriatal dopaminergic pathway. J Neurosci 18:4732-4743.

8. Day M, Wang Z, Ding J, An X, Ingham CA, Shering AF, et al. (2006): Selective elimination of glutamatergic synapses on striatopallidal neurons in Parkinson disease models. Nat Neurosci 9:251-259.

9. Scholz B, Svensson M, Alm H, Skold K, Falth M, Kultima K, et al. (2008): Striatal proteomic analysis suggests that first L-dopa dose equates to chronic exposure. PloS One 3:e1589.

10. Villalba RM, Lee $H$, Smith $Y$ (2009): Dopaminergic denervation and spine loss in the striatum of MPTP-treated monkeys. Exp Neurol 215: 220-227.

11. Corvol JC, Muriel MP, Valjent E, Feger J, Hanoun N, Girault JA, et al. (2004): Persistent increase in olfactory type G-protein alpha subunit levels may underlie D1 receptor functional hypersensitivity in Parkinson's disease. J Neurosci 24:7007-7014.

12. Taylor JL, Bishop C, Walker PD (2005): Dopamine D1 and D2 receptor contributions to L-DOPA-induced dyskinesia in the dopaminedepleted rat. Pharmacol Biochem Behav 81:887-893.

13. Aubert I, Guigoni C, Håkansson K, Li Q, Dovero S, Barthe N, et al. (2005): Increased D1 dopamine receptor signaling in levodopainduced dyskinesia. Ann Neurol 57:17-26.

14. Westin JE, Vercammen L, Strome EM, Konradi C, Cenci MA (2007): Spatiotemporal pattern of striatal ERK1/2 phosphorylation in a rat 
model of L-DOPA-induced dyskinesia and the role of dopamine D1 receptors. Biol Psychiatry 62:800-810.

15. Delfino M, Kalisch R, Czisch M, Larramendy C, Ricatti J, Taravini IR, et al. (2007): Mapping the effects of three dopamine agonists with different dyskinetogenic potential and receptor selectivity using pharmacological functional magnetic resonance imaging. Neuropsychopharmacol 32:1911-1921.

16. Darmopil S, Martin AB, De Diego IR, Ares S, Moratalla R (2009): Genetic inactivation of dopamine D1 but not D2 receptors inhibits L-DOPAinduced dyskinesia and histone activation. Biol Psychiatry 66:603-613.

17. Feyder M, Bonito-Oliva A, Fisone G (2011): L-dopa-induced dyskinesia and abnormal signaling in striatal medium spiny neurons: Focus on dopamine D1 receptor-mediated transmission. Front Behav Neurosci 5:71. doi:10.3389/fnbeh.2011.00071.

18. Fasano S, D'Antoni A, Orban PC, Valjent E, Putignano E, Vara $H$, et al. (2009): Ras-guanine nucleotide-releasing factor 1 (Ras-GRF1) controls activation of extracellular signal-regulated kinase (ERK) signaling in the striatum and long-term behavioral responses to cocaine. Biol Psychiatry 66:758-768.

19. Murer MG, Moratalla R (2011): Striatal signaling in L-dopa-induced dyskinesia: Common mechanisms with drug abuse and long term memory involving D1 dopamine receptor stimulation. Front Neuroanat 5:51. doi:10.3389/fnana.2011.00051.

20. Robinson TE, Kolb B (1997): Persistent structural modifications in nucleus accumbens and prefrontal cortex neurons produced by previous experience with amphetamine. J Neurosci 17:8491-8497.

21. Robinson TE, Gorny G, Mitton E, Kolb B (2001): Cocaine selfadministration alters the morphology of dendrites and dendritic spines in the nucleus accumbens and neocortex. Synapse 39:257-266.

22. Norrholm SD, Bibb JA, Nestler EJ, Ouimet CC, Taylor JR, Greengard P (2003): Cocaine-induced proliferation of dendritic spines in nucleus accumbens is dependent on the activity of cyclin-dependent kinase-5. Neurosci 116:19-22.

23. Ferrario CR, Gorny G, Crombag HS, Li Y, Kolb B, Robinson TE (2005): Neural and behavioral plasticity associated with the transition from controlled to escalated cocaine use. Biol Psychiatry 58:751-759.

24. Agatsuma S, Dang MT, Li Y, Hiroi N (2010): N-methyl-D-aspartic acid receptors on striatal neurons are essential for cocaine cue reactivity in mice. Biol Psychiatry 67:778-780.

25. Dumitriu D, Laplant Q, Grossman YS, Dias C, Janssen WG, Russo SJ, et al. (2012): Subregional, dendritic compartment, and spine subtype specificity in cocaine regulation of dendritic spines in the nucleus accumbens. J Neurosci 32:6957-6966.

26. Pavon N, Martin AB, Mendialdua A, Moratalla R (2006): ERK phosphorylation and FosB expression are associated with L-DOPA-induced dyskinesia in hemiparkinsonian mice. Biol Psychiatry 59:64-74.

27. Granado N, Ortiz O, Suarez LM, Martin ED, Cena V, Solis JM, Moratalla R (2008): D1 but not D5 dopamine receptors are critical for LTP, spatial learning, and LTP-Induced arc and zif268 expression in the hippocampus. Cereb Cortex 18:1-12.

28. Elston GN, Benavides-Piccione R, DeFelipe J (2001): The pyramidal cell in cognition: A comparative study in human and monkey. J Neurosci 21:RC163.

29. Kawaguchi Y (1993): Physiological, morphological, and histochemical characterization of three classes of interneurons in rat neostriatum. J Neurosci 13:4908-4923.

30. Santini E, Valjent E, Usiello A, Carta M, Borgkvist A, Girault JA, et al. (2007): Critical involvement of CAMP/DARPP-32 and extracellular signal-regulated protein kinase signaling in L-DOPA-induced dyskinesia. J Neurosci 27:6995-7005.

31. Santini E, Alcacer C, Cacciatore S, Heiman M, Hervé D, Greengard P, et al. (2009): L-DOPA activates ERK signaling and phosphorylates histone $\mathrm{H} 3$ in the striatonigral médium spiny neurons of hemiparkinsonian mice. J Neurochem 108:621-633.

32. Calabresi P, Mercuri NB, Sancesario G, Bernardi G (1993): Electrophysiology of dopamine-denervated striatal neurons. Implications for Parkinson's disease. Brain 116:433-452.

33. Calabresi P, Centonze D, Bernardi G (2000): Electrophysiology of dopamine in normal and denervated striatal neurons. Trends Neurosci 23(suppl):S57-S63.

34. Azdad K, Chavez M, Don Bischop P, Wetzelaer P, Marescau B, De Deyn PP, et al. (2009): Homeostatic plasticity of striatal neurons intrinsic excitability following dopamine depletion. PloS One 4:e6908.
35. Albin RL, Young AB, Penney JB (1989): The functional anatomy of basal ganglia disorders. Trends Neurosci 12:366-375.

36. Jenner P (2008): Molecular mechanisms of L-DOPA-induced dyskinesia. Nat Neurosci 9:665-677.

37. Day M, Wokosin D, Plotkin JL, Tian X, Surmeier DJ (2008): Differential excitability and modulation of striatal médium spiny neurons dendrites. J Neurosci 28:11603-11614.

38. Cepeda C, André VM, Yamazaki I, Wu N, Kleiman-Weiner M, Levine MS (2008): Differential electrophysiological properties of dopamine D1 and D2 receptors-containing striatal medium-sized spiny neurons. Eur J Neurosci 27:671-682.

39. Meshul CK, Emre N, Nakamura CM, Allen C, Donohue MK, Buckman JF (1999): Time-dependent changes in striatal glutamate synapses following a 6-hydroxydopamine lesion. Neurosci 88:1-16.

40. Dupre KB, Ostock CY, Eskow Jaunarajs KL, Button T, Savage LM, Wolf W, Bishop C (2011): Local modulation of striatal glutamate efflux by serotonin $1 \mathrm{~A}$ receptor stimulation in dyskinetic, hemiparkinsonian rats. Exp Neurol 229:288-299.

41. Doig NM, Moss J, Bolam JP (2010): Cortical and thalamic innervation of direct and indirect pathway medium-sized spiny neurons in mouse striatum. J Neurosci 30:14610-14618.

42. Ballion B, Frenois F, Zold CL, Chetrit J, Murer MG, Gonon F (2009): D2 receptor stimulation, but not D1, restores striatal equilibrium in a rat model of Parkinsonism. Neurobiol Dis 35:376-384.

43. André VM, Cepeda C, Cummings DM, Jocoy EL, Fisher YE, William Yang X, Levine MS (2010): Dopamine modulation of excitatory currents in the striatum is dictated by the expression of D1 or D2 receptors and modified by endocannabinoids. Eur J Neurosci 31:14-28.

44. Gardoni F, Picconi B, Ghiglieri V, Polli F, Bagetta V, Bernardi G, et al. (2006): A critical interaction between NR2B and MAGUK in L-DOPA induced dyskinesia. J Neurosci 26:2914-2922.

45. Hallett PJ, Spoelgen R, Hyman BT, Standaert DG, Dunnah AW (2006): Dopamine D1 activation potentiates striatal NMDA receptors by tyrosine phosphorylation-dependent subunit trafficking. J Neurosci 26: 4690-4700

46. Porras G, Berthet A, Dehay B, Li Q, Ladepeche L, Normand E, et al. (2012): PSD-95 expression controls L-DOPA dyskinesia through dopamine D1 receptors trafficking. J Clin Invest 122:3977-3989.

47. Plotkin JL, Day M, Surmeier DJ (2011): Synaptically driven state transitions in distal dendrites of striatal spiny neurons. Nat Neurosci 14:881-888.

48. Nisenbaum ES, Mermelstein PG, Wilson CJ, Surmeier DJ (1998): Selective blockade of a slowly inactivating potassium current in striatal neurons by (+/-) 6-chloro-APB hydrobromide (SKF82958). Synapse 29:213-224

49. Jaidar O, Carrillo-Reid L, Hernandez A, Drucker-Colin R, Bargas J, Hernandez-Cruz A (2010): Dynamics of the Parkinsonian striatal microcircuit: Entrainment into a dominant network state. J Neurosci 30:11326-11336.

50. Hernandez-Lopez S, Bargas J, Surmeier DJ, Reyes A, Galarraga E (1997): D1 receptor activation enhances evoked discharge in neostriatal medium spiny neurons by modulating an L-type Ca2+ conductance. J Neurosci 17:3334-3342.

51. Gerfen CR, Surmeier DJ (2011): Modulation of striatal projection systems by dopamine. Annu Rev Neurosci 34:441-466.

52. Calabresi P, Mercuri N, Stanzione P, Stefani A, Bernardi G (1987): Intracellular studies on the dopamine-induced firing inhibition of neostriatal neurons in vitro: Evidence for D1 receptor involvement. Neurosci 20:757-571.

53. Boraud T, Bezard E, Bioulac B, Gross CE (2001): Dopamine agonistinduced dyskinesias are correlated to both firing pattern and frequency alterations of pallidal neurones in the MPTP-treated monkey. Brain 124:546-557.

54. Guigoni C, Dovero S, Aubert I, Li Q, Bioulac BH, Bloch B, et al. (2005): Levodopa-induced dyskinesia in MPTP-treated macaques is not dependent on the extent and pattern of nigrostrial lesioning. Eur $J$ Neurosci 22:283-287.

55. Hirano S, Asanuma K, Ma Y, Tang C, Feigin A, Dhawan V, et al. (2008): Dissociation of metabolic and neurovascular responses to levodopa in the treatment of Parkinson's disease. J Neurosci 28:4201-4209.

56. Halje $P$, Tamtè $M$, Richter $U$, Mohammed $M$, Cenci MA, Petersson $P$ (2012): Levodopa-induced dyskinesia is strongly associated with resonant cortical oscillations. J Neurosci 32:16541-16551. 